\title{
Photocatalysis/catalysis by innovative TiN and TiN-Ag surfaces inactivate bacteria under visible light
}

\author{
S. Rtimi ${ }^{\mathrm{a}, \mathrm{e}}$, O. Baghriche ${ }^{\mathrm{a}}$, R. Sanjines ${ }^{\mathrm{b}}$, C. Pulgarin ${ }^{\mathrm{a}, * *}$, M. Ben-Simon $^{\mathrm{c}}, \mathrm{J}^{-}-$C. Lavanchy $^{\mathrm{d}}$, A. Houas $^{\mathrm{e}}$, J. Kiwi ${ }^{\mathrm{f}, *}$
}

a Ecole Polytechnique Fédérale de Lausanne, EPFL-SB-ISIC-GPAO, Station 6, CH-1015, Lausanne, Switzerland

${ }^{\mathrm{b}}$ Ecole Polytechnique Fédérale de Lausanne, EPFL-SB-IPMC-LNNME, Bat PH, Station 3, CH-1015, Lausanne, Switzerland

${ }^{\mathrm{c}}$ Ecole Polytechnique Fédérale de Lausanne, EPFL-ENAC-IIEGR-CEL, Bat GC, Station 18, CH-1015, Lausanne, Switzerland

' Université de Lausanne, IMG, Centre d'Analyse Minérale, Bat Anthropole, CH-1015, Lausanne, Switzerland

e UR Catalyse/Matériaux pour l'Environnement et Procédés (URCMEP), Faculté Sciences Gabès, Gabès, 6072, Tunisia

${ }^{\mathrm{f}}$ Ecole Polytechnique Fédérale de Lausanne, EPFL-SB-ISIC-LPI, Bat Chimie, Station 6, CH-1015, Lausanne, Switzerland

\section{A R T I C L E I N F O}

\section{Article history:}

Received 6 March 2012

Received in revised form 27 April 2012

Accepted 27 April 2012

Available online $\mathrm{xxx}$

\section{Keywords:}

TiN

E. coli inactivation

Polyester

Visible light

TiN-Ag sputtering DC and DCP

\begin{abstract}
A B S T R A C T
This study presents the design, preparation, testing and characterization of TiN and TiN-Ag nanoparticulate films leading to photocatalytic and catalytic inactivation of Escherichia coli. When Ti was sputtered in $\mathrm{N}_{2}$ atmosphere, the TiN films unexpectedly revealed semiconductor properties when irradiated under visible light due to the formation of $\mathrm{TiO}_{2}$ showing absorption in the visible spectral region. In TiN-Ag films, Ag enhances the photocatalytic activity of TiN leading to faster bacterial inactivation. Evidence for the presence of $\mathrm{TiO}_{2}$ and TiN in the films is presented by XPS. The TiN layers 50 nm thick sputtered by DC for $3 \mathrm{~min}$ led to complete inactivation of $E$. coli within $120 \mathrm{~min}$. But TiN layers with a thickness $>50 \mathrm{~nm}$ hinder the surface diffusion of charges reducing bacterial inactivation. The rate of TiN deposition was $\sim 1.4 \times 10^{15}$ atoms TiN $/ \mathrm{cm}^{2} \mathrm{~s}$. For the TiN-polyester samples under visible light a $3 \log _{10}$ bacterial reduction (99.9\%) was observed within $30 \mathrm{~min}$ while for TiN-Ag samples the same bacterial reduction was attained within $\sim 15 \mathrm{~min}$. The absorption of the TiN-Ag samples in Kubelka-Munk (KM) units was directly proportional to the $E$. coli inactivation kinetics. TiN-Ag plasmon nanostructures are concurrently formed under low intensity visible light and accelerated bacterial inactivation. This study shows that TiN films have the potential to replace Ag-based disinfection materials leaching Ag into the environment.
\end{abstract}

(c) 2012 Elsevier B.V. All rights reserved.

\section{Introduction}

Thin film sputtered TiN is widely used for protective layers presenting high chemical resistance to corrosion/oxidation, in the electrical, machinery-tools industry and interconnectors $[1,2]$. The high melting point, adhesion and diffusion barrier for metal ions in interconnectors has been reported [3]. Kelly has recently reported TiN and other nitrides co-sputtered with $\mathrm{Ag}$ as antimicrobial surfaces inactivating Gram-negative and Gram-positive bacteria in the dark [4]. Ag and $\mathrm{Cu}$ have also been sputtered on TiN rig metals in $\mathrm{Ar}-\mathrm{N}_{2}$ atmosphere [5]. Ag is immiscible with TiN and films of AgN are known to be unstable. Ag can be sputtered on TiN or cosputtered producing an $\mathrm{Ag}$ embedded composite structure with TiN. We have recently reported the antibacterial activity of sputtered $\mathrm{ZrN}$ nanoparticulate films on polyester. A 15 min sputtered

\footnotetext{
* Corresponding author. Tel.: +4121693 36 21; fax: +41216934111.

** Corresponding author. Tel.: +41 21693 4720; fax: +41 216935690.

E-mail addresses: cesar.pulgarin@epfl.ch (C. Pulgarin), John.Kiwi@epfl.ch (J. Kiwi).
}

ZrN film led to bacterial inactivation within $\sim 8 \mathrm{~h}$. When Ag was subsequently sputtered on $\mathrm{ZrN}$ for $20 \mathrm{~s}$, the Escherichia coli inactivation occurred within $90 \mathrm{~min}$ in the dark [6].

During the last decade, there has been increased interest in innovative antibacterial coatings due to the increasing resistance of pathogenic bacteria to synthetic antibiotics. Silver nanoparticles (NPs) present antimicrobial properties when deposited on surfaces and textiles. Sputtering has been used for Ag-incorporation on textiles [7-11]. Ag-nanofilms present acceptable adhesion and adequate bacterial inactivation kinetics. But when washing some $\mathrm{Ag}$ leaches out and becomes an undesired environmental problem [12-15]. Silver based antimicrobials are of interest due to the non-toxicity of the active Ag-ions to human cells and many studies address this point describing Ag-nanoparticle cell compatibility [16-18].

The present study sputtering TiN-Ag is directed toward the preparation of hybrid TiN-Ag. The Ag-component enhances the TiN antibacterial activity and without inducing bacterial resistance to antibiotics when administered for longer times $[19,20]$. Biofilms once formed are hard to remove since they adhere strongly to all kind of surfaces like textiles, glass, prostheses and catheters [21,22]. 
TIN/TIN-Ag films on hospital textiles like the one suggested in this study should avoid the spreading toxic bacteria

The objectives of this study are: (a) to present the first systematic and comprehensive report on the bactericide action of TiN nanoparticle films activated by light in the visible range, (b) to explain the unexpected the light induced activity of TiN films, (c) to report the E. coli inactivation activated by commercial actinic light on TiN surfaces, (d) to present the evidence for Ag added to the TiN surfaces through the creation of resonant surface plasmons and (e) to show the direct correlation between the applied light intensity and the light absorption by the TiN-Ag-layers and the bacterial inactivation kinetics.

\section{Experimental}

\subsection{Sputtering of TiN underlayers and TiN-Ag films. Thickness calibration}

The TiN and TiN-Ag thin films have been deposited onto polyester substrates at room temperature without substrate heating by using two confocal magnetron-sputtering systems. The polyester samples were $2 \mathrm{~cm} \times 2 \mathrm{~cm}$ in size. Before the deposition of the films the residual pressure $P_{\mathrm{r}}$ in the sputtering chamber was typically $P_{\mathrm{r}} \leq 10^{-4} \mathrm{~Pa}$. The substrate-to-target distance was fixed at $10 \mathrm{~cm}$. The TiN thin films have been deposited by reactive DC magnetron sputtering (DC) using a $5 \mathrm{~cm}$ diameter Ti target 99.99 at.\% (Kurt J. Lesker, East Sussex, UK) in an $\mathrm{Ar}+\mathrm{N}_{2}$ atmosphere. The total working pressure $P_{\mathrm{T}}=\left(P_{A r}+P_{\mathrm{N}_{2}}\right)$ was fixed at $0.5 \mathrm{~Pa}$ and the ratio $P_{\mathrm{N}_{2}} / P_{\mathrm{T}}=4.5 \%$. The applied sputtering current on the Ti target was fixed at $250 \mathrm{~mA}$ providing a power of $112 \mathrm{~W}(U=-450 \mathrm{~V})$ and a current density of $12.7 \mathrm{~mA} / \mathrm{cm}^{2}$. DCP was used to sputter $\mathrm{Ag}$ and was operated at $50 \mathrm{kHz}$ with $15 \%$ reversed voltage. The sputtering current was fixed at $280 \mathrm{~mA}\left(14.3 \mathrm{~mA} / \mathrm{cm}^{2}\right)$ providing a negative voltage of $-500 \mathrm{~V}, 75 \mathrm{~V}$ as reverse voltage $(15 \%$ of $500 \mathrm{~V})$ and a power of $140 \mathrm{~W}$. Details regarding sputtering Ag on different textiles using the unit available in our laboratory have been described recently $[6,10,11,23,24]$.

The polyester used corresponds to the EMPA test cloth sample no. 407. It is a polyester Dacron polyethylene-terephthalate, type 54 spun, plain weave ISO 105-F04 used for color fastness determinations. The thermal stability of Dacron polyethylene terephthalate was $115^{\circ} \mathrm{C}$ for long-range operation and $140^{\circ} \mathrm{C}$ for times $\leq 1 \mathrm{~min}$. The thickness of the polyester was $\pm 130 \mu \mathrm{m} \pm 10 \%$.

The calibration of the TiN and TiN-Ag film thickness deposited by DC and DCP on Si-wafers are shown in Fig. 1. The film thickness was determined with a profilometer (Alphastep500, TENCOR) and the values presented an error of $\pm 10 \%$. The layers of TiN were sputtered by DC and taking $10^{15}$ atoms/layer/ $\mathrm{cm}^{2}$ being each layer $0.2 \mathrm{~nm}$ thick [25], makes within $3 \mathrm{~min}$ in Fig. 1, a thickness of $50 \mathrm{~nm}$ with $2.5 \times 10^{17}$ atoms $/ \mathrm{cm}^{2}$. This data allows the estimation of a deposition rate of $1.4 \times 10^{15} \mathrm{TiN} / \mathrm{cm}^{2} \mathrm{~s}$. The $\mathrm{Ag}$ was then sputtered on the TiN under layers by DCP since recent work in our laboratory showed a faster bacterial inactivation of $E$. coli by DCP compared with DC-deposition [24]. Fig. 1 shows that $50 \mathrm{~nm}$ more were added within 3 min when Ag was sputtered. This allows the estimation of a rate of deposition for $\mathrm{Ag}$ of $1.4 \times 10^{15} \mathrm{Ag} / \mathrm{cm}^{2} \mathrm{~s}$.

\subsection{X-ray fluorescence determination of the Ag and Ti on polyester samples (XRF)}

The Ag-content on the polyester was evaluated by X-ray fluorescence. By this technique, each element emits an X-ray of a certain wavelength associated with its particular atomic number. The spectrometer used was RFX, PANalytical PW2400. The weight percentage of $\mathrm{Ag}$ and $\mathrm{Ti}$ in the $\mathrm{Ag}$ and $\mathrm{TiN}-\mathrm{Ag}$ samples at different

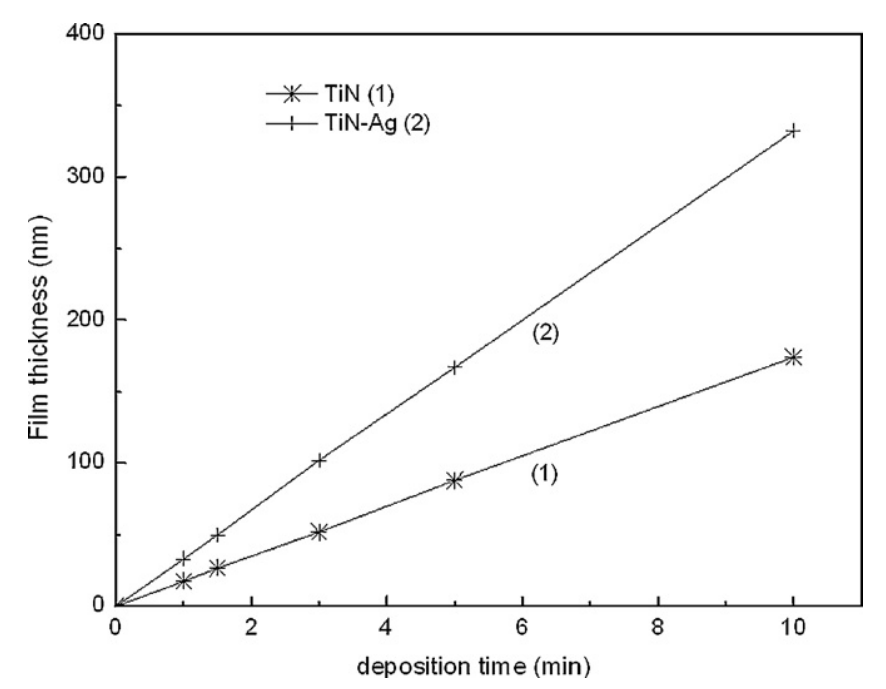

Fig. 1. Film thickness as a function of sputtering time for TiN and TiN-Ag samples.

sputtering times is shown in Table 1 . The most effective TiN-Ag photocatalyst (TiN-Ag ( $3 \mathrm{~min} / 20 \mathrm{~s}$ ) had an Ag-content of $0.023 \mathrm{wt} \%$ $\mathrm{Ag} / \mathrm{wt}$ polyester and $0.29 \mathrm{wt} \% \mathrm{Ti} / \mathrm{wt}$ polyester. In the last raw the Ag was sputtered before the TiN on the polyester sample.

\subsection{Evaluation of the bacterial inactivation of E. coli on sputtered polyester}

The samples of Escherichia coli (E. coli K12) was obtained from the Deutsche Sammlung von Mikroorganismen und Zellkulturen GmbH (DSMZ) ATCC23716, Braunschweig, Germany, to test the antibacterial activity of the Ag-polyester fabrics. The polyester fabrics were sterilized by autoclaving at $121^{\circ} \mathrm{C}$ for $2 \mathrm{~h} .20 \mu \mathrm{L}$ aliquot of culture with an initial concentration of $10^{8} \mathrm{CFU} \mathrm{mL}^{-1}$ in $\mathrm{NaCl} / \mathrm{KCl}$ $(\mathrm{pH} 7)$ was placed on each coated and uncoated (control) polyester fabric. The samples were placed on Petri dish provided with a lid to prevent evaporation. After each determination, the fabric was transferred into a sterile $2 \mathrm{~mL}$ Eppendorf tube containing $1 \mathrm{~mL}$ autoclaved $\mathrm{NaCl} / \mathrm{KCl}$ saline solution. This solution was subsequently mixed thoroughly using a Vortex for $3 \mathrm{~min}$. Serial dilutions were made in $\mathrm{NaCl} / \mathrm{KCl}$ solution. A $100-\mu \mathrm{L}$ sample of each dilution was pipetted onto a nutrient agar plate and then spread over the surface of the plate using standard plate method. Agar plates were incubated lid down, at $37^{\circ} \mathrm{C}$ for $24 \mathrm{~h}$ before colonies were counted. The bacterial data reported were replicated three times. To verify that no re-growth of $E$. coli occurs after the total inactivation observed in the first disinfection cycle, the TiN-Ag nanoparticle film is incubated for $24 \mathrm{~h}$ at $37^{\circ} \mathrm{C}$. Then bacterial suspension of $100 \mu \mathrm{m}$ is deposited on 3 Petri dishes to obtain the replica samples of the bacterial counting. These samples are incubated at $37^{\circ} \mathrm{C}$ for $24 \mathrm{~h}$. No bacterial re-growth was observed.

Table 1

$\mathrm{X}$-ray fluorescence (XRF) of Ag-polyester and TiN-Ag polyester sputtered samples.

\begin{tabular}{lllll}
\hline $\mathrm{Ag}(10 \mathrm{~s})$ on polyester & 0.08 & 0.08 & - & - \\
$\mathrm{Ag}(20 \mathrm{~s})$ on polyester & 0.13 & 0.14 & - & - \\
$\mathrm{Ag}(30 \mathrm{~s})$ on polyester & 0.15 & 0.16 & - & - \\
$\mathrm{TiN}(3 \mathrm{~min})$ on polyester & - & - & 0.34 & 0.57 \\
$\mathrm{TiN}-\mathrm{Ag}(3 \mathrm{~min} / 10 \mathrm{~s})$ on polyester & 0.013 & 0.014 & 0.23 & 0.38 \\
$\mathrm{TiN}-\mathrm{Ag}(3 \mathrm{~min} / 20 \mathrm{~s})$ on polyester & 0.023 & 0.025 & 0.29 & 0.49 \\
$\mathrm{TiN}-\mathrm{Ag}(3 \mathrm{~min} / 30 \mathrm{~s})$ on polyester & 0.05 & 0.06 & 0.018 & 0.03 \\
$\mathrm{Ag}-\mathrm{TiN}(20 \mathrm{~s} / 3 \mathrm{~min})$ on polyester & 0.035 & 0.037 & 0.32 & 0.54 \\
\hline
\end{tabular}




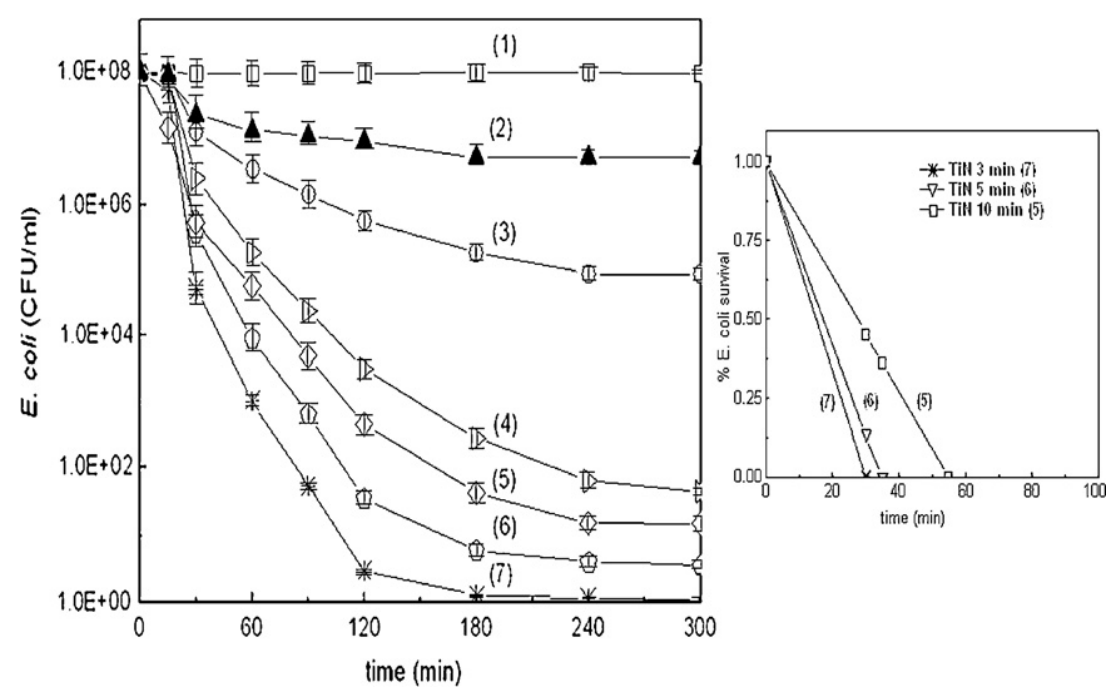

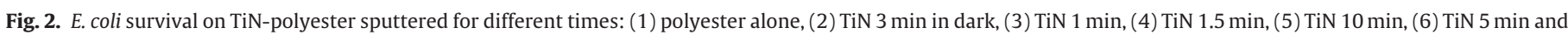

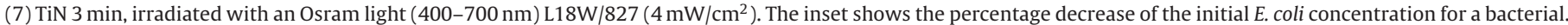

\subsection{Irradiation of samples during the bacterial inactivation of E. coli}

The irradiation of the polyester samples was carried out in a cavity provided with tubular Osram Lumilux 18W/827 actinic lamps. These lamps have a visible emission spectrum between 400 and $700 \mathrm{~nm}$ with an integral output of $1.2 \mathrm{~mW} / \mathrm{cm}^{2}$ resembling the light distribution found in solar irradiation. The bacterial inactivation was also carried out with actinic lamps Osram L18/840 used generally in hospitals emitting light in the visible region. These lamps present a more efficient compromise of energy consumption per irradiated lumen. The bacterial inactivation kinetics is reported for diverse light intensities for both lamps.

\subsection{Inductively coupled plasma spectrometry (ICPS)}

The Finnigan ${ }^{\mathrm{TM}}$ ICPS used was equipped with a double focusing reverse geometry mass spectrometer presenting an extremely low background signal and high ion-transmission coefficient. The spectral signal resolution was $1.2 \times 10^{5} \mathrm{cps} / \mathrm{ppb}$ and the detection limit of $0.2 \mathrm{ng} / \mathrm{L}$

\subsection{Diffuse reflectance spectroscopy of polyester samples}

Diffuse reflectance spectroscopy was carried out using a PerkinElmer Lambda 900 UV-vis-NIR spectrometer provided for with a PELA-1000 accessory within the wavelength range of $200-800 \mathrm{~nm}$ and a resolution of one $\mathrm{nm}$. The absorption of the samples was plotted in Kubelka-Munk (KM) arbitrary units vs wavelength.

\subsection{Transmission electron microscopy and energy dispersive spectroscopy (EDS) studies}

A Philips CM-12 (field emission gun, $300 \mathrm{kV}, 0.17 \mathrm{~nm}$ resolution) microscope at $120 \mathrm{kV}$ was used to measure grain size of the Agfilms. The textiles were embedded in epoxy resin 45359 Fluka and the fabrics were cross-sectioned with an ultramicrotome (Ultracut E) and at a knife angle at $35^{\circ}$. Images were taken in Bright Field (BF) mode for the samples sputtered by DC and DCP. EDS was used to determine the quantitative chemical sample surface composition at the current beam position. Atoms of different chemical elements emit X-rays with a different specific energy.

\subsection{X-ray photoelectron spectroscopy of Ag-polyester samples} (XPS)

An AXIS NOVA photoelectron spectrometer (Kratos Analytical, Manchester, UK) equipped with monochromatic Al $\mathrm{K} \alpha$ $(h v=1486.6 \mathrm{eV})$ anode was used during the study. The electrostatic charge effects on the samples were compensated by means of the low-energy electron source working in combination with a magnetic immersion lens. The carbon $\mathrm{C} 1 \mathrm{~s}$ line with position at $284.6 \mathrm{eV}$ was used as a reference to correct the charging effect. The quantitative surface atomic concentration of some elements was determined from peak areas using sensitivity factors [26]. Spectrum background was subtracted according to Shirley [27]. The XPS spectra for the Ag-species were analyzed by means of spectra deconvolution software (CasaXPS-Vision 2, Kratos Analytical UK).

\section{Results and discussion}

\subsection{Bacterial inactivation by light activated TiN, TiN-Ag and Ag-polyester surfaces}

Fig. 2 shows the inactivation of $E$. coli in the dark and under light by TiN-sputtered polyester samples. Fig. 2 shows the beneficial effect of the visible light revealing the semiconductor behavior of the coating sputtered on polyester. The TiN-polyester samples under visible light irradiation inactivate completely $E$. coli within 120-140 min. A $3 \log _{10}$ bacterial reduction (99.9\%) was observed within $\sim 30 \mathrm{~min}$ and this result is shown in the right hand side insert to Fig. 2.

The formation of $\mathrm{TiO}_{2}$ can be understood in terms of: (a) the partial oxidation of TiN takes place in the presence of an oxygen source due to the residual $\mathrm{H}_{2} \mathrm{O}$ vapor in the sputtering chamber at the residual pressure $P_{\mathrm{r}}=10^{-4} \mathrm{~Pa}$. This pressure is representative of about $10^{15}$ molecules $/ \mathrm{cm}^{2} \mathrm{~s}$; there are sufficient O-radicals available to induce partial oxidation of TiN films $[11,24]$ and (b) the films can oxidize after the deposition when exposed to air and during the sterilization process (autoclaving at $121^{\circ} \mathrm{C}$ ).

In Fig. 2, increasing bacterial inactivation kinetics was observed as the sputtering time increases from 1 to $3 \mathrm{~min}$ as shown by traces $2,3,7$ since the amount of generated charges increases with a growing number of TiN layers up to a certain limit. Traces 5 and 6 for 10 and 5 min sputtering times respectively show slower bacterial inactivation kinetics compared to trace 7 ( $3 \mathrm{~min}$ ). This is due to the increase in the sputtered layer thickness and leading to bulk inward 


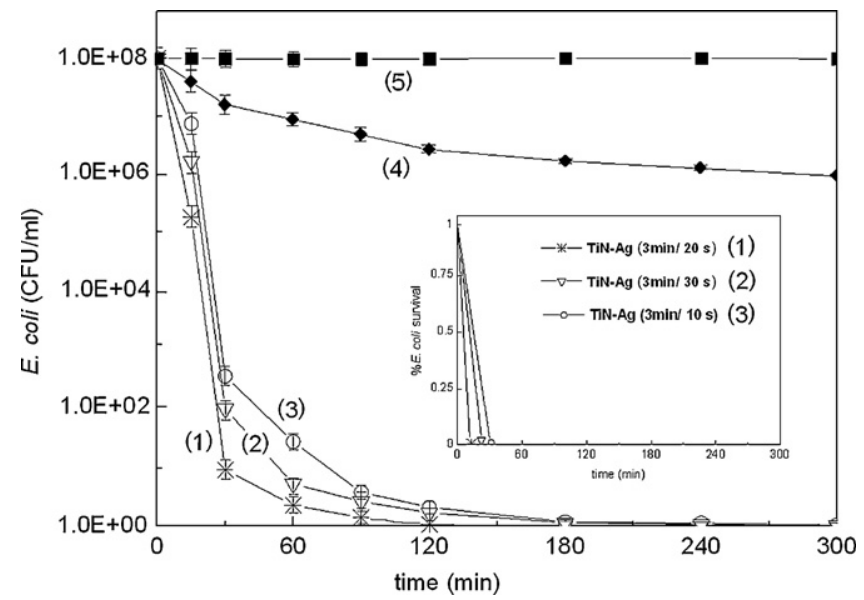

Fig. 3. E. coli survival on TiN-Ag polyester sputtered for different times and irradiated with an Osram light (400-700 nm) L18W/827 $\left(4 \mathrm{~mW} / \mathrm{cm}^{2}\right)$. Traces (1): TiN-Ag $3 \mathrm{~min} / 20 \mathrm{~s}$; (2): TiN-Ag $3 \mathrm{~min} / 30 \mathrm{~s}$; (3): TiN-Ag $3 \mathrm{~min} / 10 \mathrm{~s}$; (4): TiN-Ag $3 \mathrm{~min} / 20 \mathrm{~s}$ in dark and (5): polyester alone. The inset shows the percentage decrease of the initial E. coli concentration for a bacterial reduction of $3 \log _{10}$.

diffusion of the charge carriers $[21,25,28,29]$. These charge carriers are responsible for the electrostatic attraction with the bacteria. After 3 min sputtering time, the TiN coated polyester presents the highest amount of active sites/carriers held in exposed positions leading to the shortest bacterial inactivation.

Fig. 3 shows the bacterial inactivation of $E$. coli for TiN/Ag films. The deposition time of the TiN under layer film was fixed at $3 \mathrm{~min}$ while of the deposited amount of the Ag was tuned by changing the deposition time from $10 \mathrm{~s}$ to $30 \mathrm{~s}$. A 15 min irradiation period led to a $3 \log _{10}$ reduction (99.9\%) of the initial E. coli concentration as shown in the insert. Complete bacterial inactivation was observed within $\sim 60-90 \mathrm{~min}$. These results show the bactericide action of Ag-sputtered of the TiN layers increasing the bacterial inactivation kinetics compared to Fig. 2. A darker-gray metallic Ag-color was observed on the polyester with increasing sputtering time. Migration/aggregation of the $\mathrm{Ag}$-particles lead to stable agglomerates. The dark gray color corresponds to the $\mathrm{Ag}_{2} \mathrm{O} / \mathrm{Ag}^{\mathrm{O}}$ with a band-gap $\left(b_{\mathrm{g}}\right)$ 0.7-1.0 eV and an absorption edge of $\sim 1000 \mathrm{~nm}$ [30]. The Agclusters have been reported not necessarily crystalline and were responsible for the darkening of the Ag-samples as a function of sputtering time [31].

Fig. 4 shows the E. coli survival on polyester Ag-surfaces sputtered for different times. That the sputtering of $\mathrm{Ag}$ for $20 \mathrm{~s}$ leads to

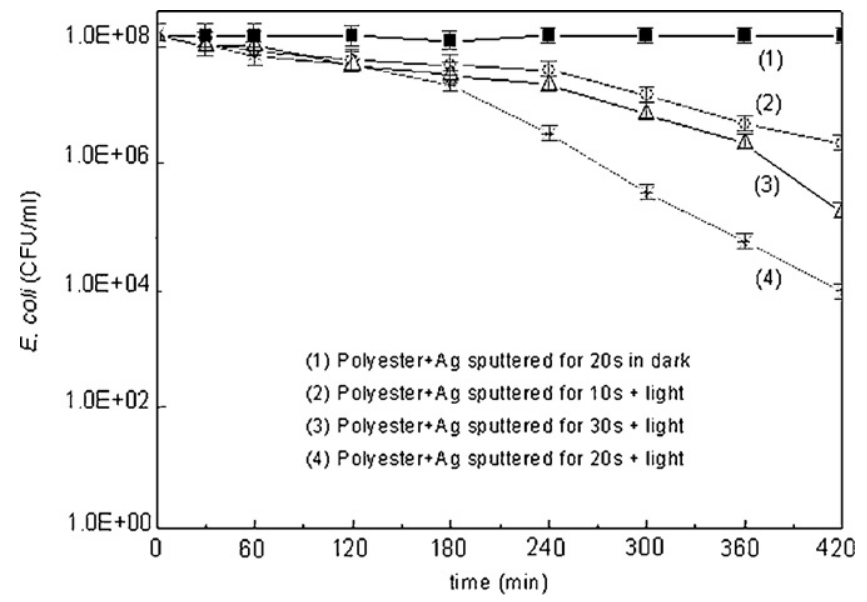

Fig. 4. E. coli survival on Ag-polyester irradiated with Osram light (400-700 nm) L18W/827 ( $4 \mathrm{~mW} / \mathrm{cm}^{2}$ ): sputtered for $10 \mathrm{~s}$ (trace 2 ); $30 \mathrm{~s}$ (trace 3 ); for $20 \mathrm{~s}$ (trace 4 ) and sputtered for $20 \mathrm{~s}$ in the dark condition (trace 1 ).
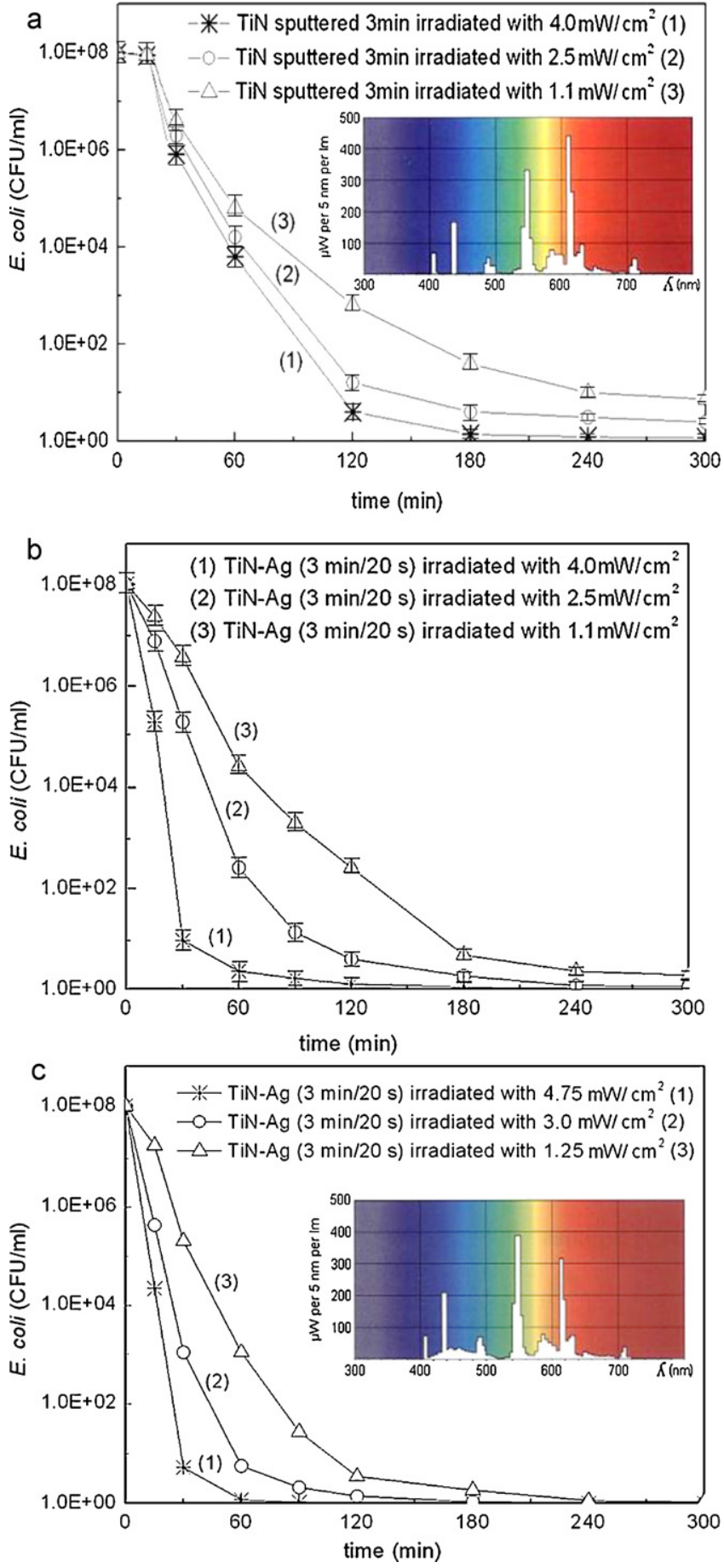

Fig. 5. (a) Survival of $E$. coli on TiN polyester sputtered for 3 min and irradiated with Osram light source (400-700 nm) $18 \mathrm{~W} / 827$. (b) Survival of E. coli on TiN-Ag polyester sputtered for $3 \mathrm{~min}$ and irradiated with an Osram light (400-700 nm) L18W/827. (c) Survival of E. coli on TiN-Ag polyester irradiated with Osram light $(400-700 \mathrm{~nm})$ L18W/840.

the best results as shown in Fig. 4, trace (4) can be rationalized by suggesting that a sputtering time of $20 \mathrm{~s}$ lead to the optimal ratio of Ag-loading/Ag cluster size with the highest amount of Ag-sites held in exposed positions on the polyester surface. The Ag-nanoparticles sputtered for times $>20$ s agglomerated to bigger units decreasing bacterial inactivation. Ag-atoms are known to be immiscible with the TiN-layer [31] and experiments co-sputtering $\mathrm{Ti}$ and $\mathrm{Ag}$ for $20 \mathrm{~s}$ in the magnetron chamber led to a TiN-Ag composite films with a slower kinetics compared to TiN-Ag ( $3 \mathrm{~min} / 20 \mathrm{~s}$ ) as reported 


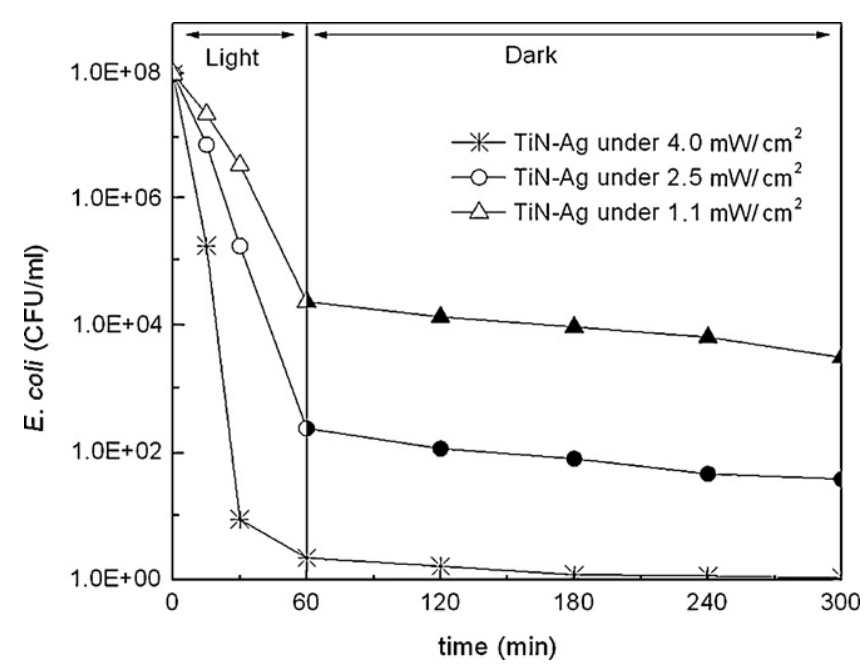

Fig. 6. Survival of $E$. coli on $\mathrm{TiN}-\mathrm{Ag}(3 \mathrm{~min} / 20 \mathrm{~s})$ polyester under Osram light $\mathrm{L} 18 \mathrm{~W} / 827(400-700 \mathrm{~nm})$ applied for $60 \mathrm{~min}$ showing the residual inactivation in the dark.

in Fig. 3. The remarkable acceleration of the bacterial inactivation kinetics observed in Fig. 3 respect to Fig. 4 for TiN-Ag films was due to the deposition of a TiN underlayer on polyester. Apparently the smooth coating on the substrate results from the intimate bonding between the nitride and the substrate. As the nitride layer nucleates the surface bonding of the ad-atoms proceeds with a high alignment over the polyester grain structure. During coalescence, the film merges without forming boundaries and leading to a smooth nitride layer [32]. This TiN continuous under layer will be shown below in the TEM section.

\subsection{Bacterial inactivation kinetics as a function of the type of lamp and light dose}

Fig. 5a presents the bacterial inactivation kinetics mediated by TiN-polyester samples under light irradiation from a visible light source Osram $18 \mathrm{~W} / 827$. It is readily seen that the bacterial inactivation kinetics by the TiN samples are strongly dependent on the light dose in the reactor cavity. Fig. 5a shows in the insert the spectral distribution of the light source.

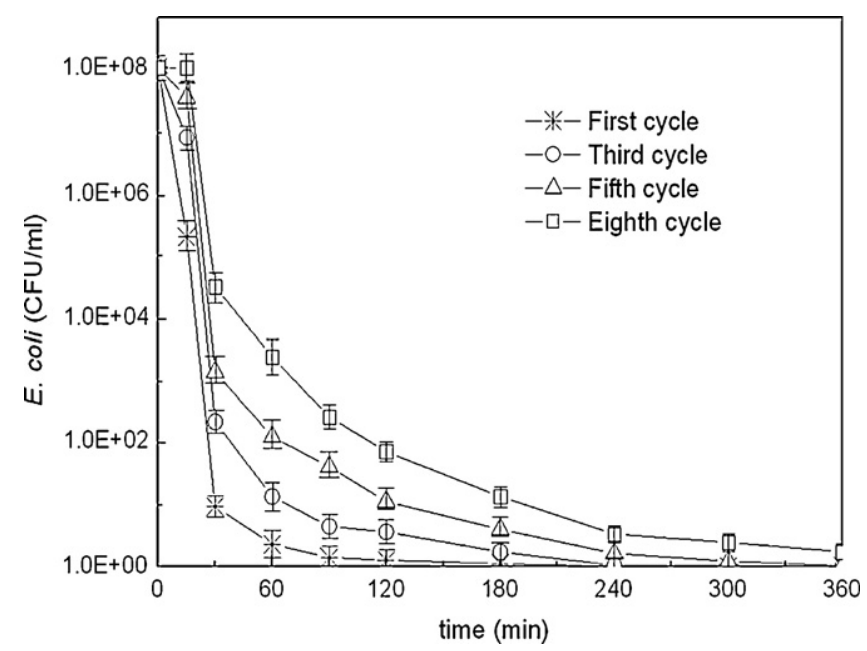

Fig. 7. Survival of $E$. coli as a function of the number of recyclings for a sample TiN$\mathrm{Ag}$ ( $3 \mathrm{~min}-20 \mathrm{~s})$ polyester up to the 8 th cycle. Osram light: $400-700 \mathrm{~nm}, 4 \mathrm{~mW} / \mathrm{cm}^{2}$ ) L18W/827 lamp.

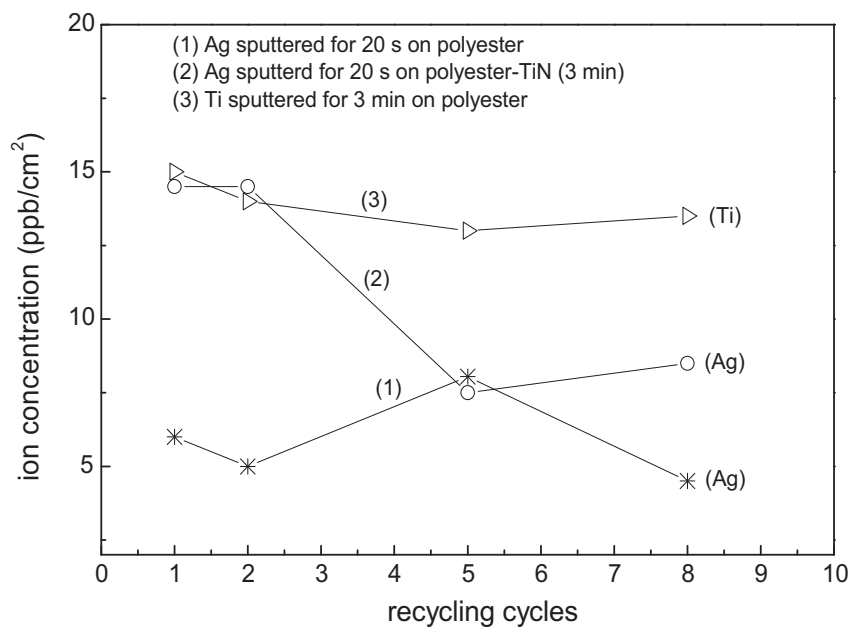

Fig. 8. Ion-coupled plasma spectrometry (ICPS) determination of Ag-ions and Tiions released during the recycling of (a) sample sputtered with Ag for 30 s (trace 1), (b) TiN-Ag (3 min- $20 \mathrm{~s}$ ) sputtered sample and (c) TiN sample sputtered sample for 3 min (trace 3 ).

The same trend was observed for the TiN-Ag samples in Fig. 5b as the one reported in Fig. 5a. Fig. 5c shows the light dose dependence for the bacterial inactivation but this time using an Osram L18W/840 light source, with a small modification in the spectral
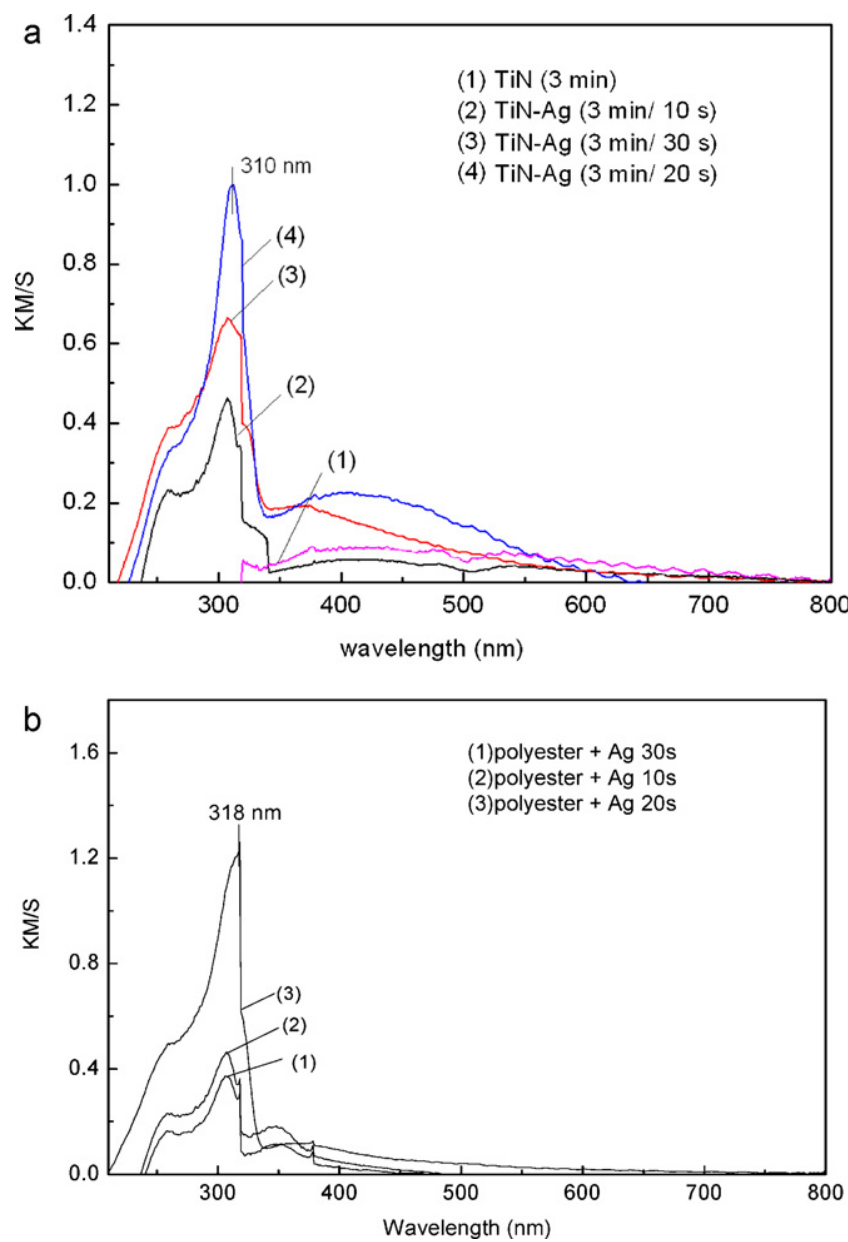

Fig. 9. (a) Diffuse reflectance spectra of TiN and TiN-Ag sputtered on polyester for different deposition times. (b) Diffuse reflectance spectra of Ag-sputtered on polyester for different deposition times. 


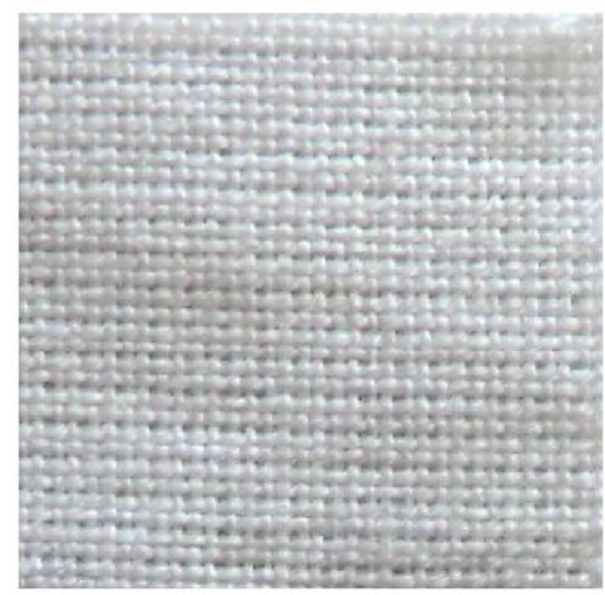

Polyester alone

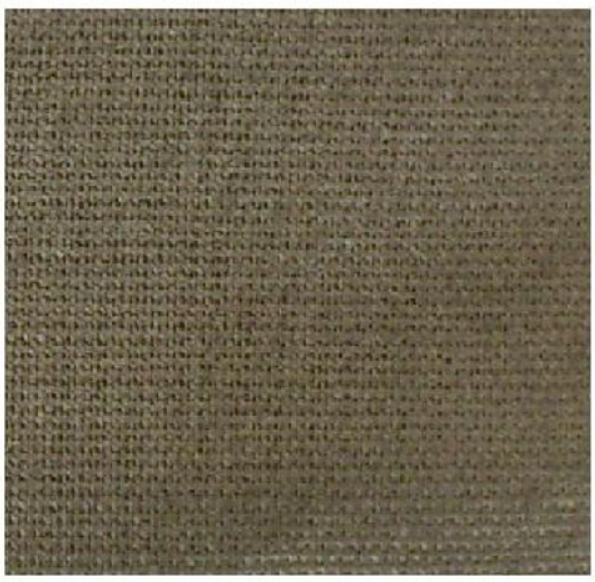

$\mathrm{Ag}(20 \mathrm{~s})$

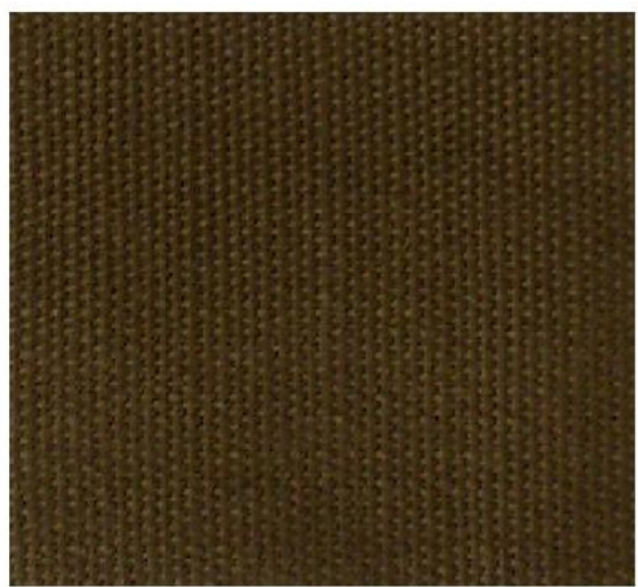

TiN (3 min)

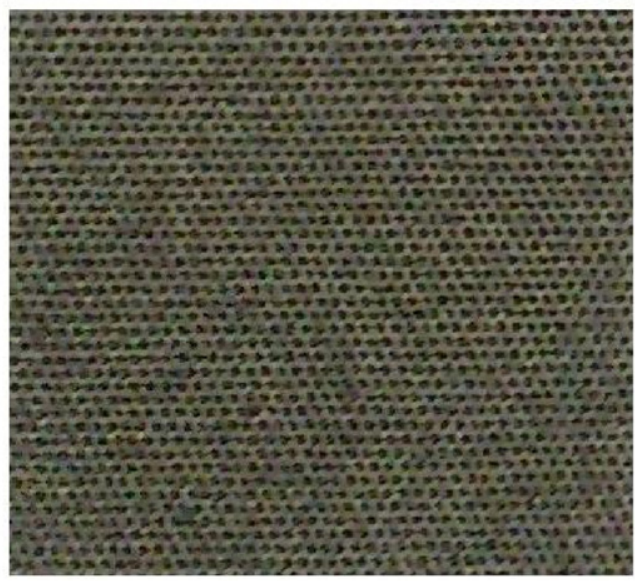

TiN-Ag (3 min/20 s)

Fig. 10. Polyester alone, polyester sputtered with TiN, Ag and TiN-Ag respectively. The samples were $2 \mathrm{~cm} \times 2 \mathrm{~cm}$.

Table 2

Surface atomic concentrations of elements during E. coli inactivation on a TiN $3 \mathrm{~min}$ sputtered sample under Osram light (400-700 nm) 18W/827 lamp.

\begin{tabular}{lllrl}
\hline TiN & O 1s & Ti 2p & N 1s & C 1s \\
\hline$t=0$ min & 19.20 & 44.74 & 13.75 & 22.31 \\
$t=0$ min (contacted 3 s with bacteria) & 23.58 & 19.58 & 6.42 & 51.66 \\
$t=30$ min (contacted with bacteria) & 29.58 & 28.96 & 6.73 & 50.41 \\
$t=60$ min (contacted with bacteria) & 31.66 & 29.40 & 7.28 & 42.09 \\
$t=120$ min (contacted with bacteria) & 32.01 & 30.13 & 6.20 & 35.05 \\
$t=180$ min (contacted with bacteria) & 32.61 & 22.37 & 5.45 & 34.73 \\
\hline
\end{tabular}

distribution compared to the light source used to irradiate samples in Fig. 5a and b, This up-to-date actinic light is currently used in hospital facilities in Switzerland and this was the reason to carry out the experiment shown in Fig. 5c.

Fig. 6 shows the residual bacterial inactivation in the absence of light when $E$. coli was irradiated in the cavity for $60 \mathrm{~min}$. The dependence on the applied light dose of the secondary process is shown for three different light intensities.

\subsection{Repetitive E. coli inactivation by recycling of a TiN-Ag sample}

Fig. 7 shows the recycling up to the 8th cycle of a TiN-Ag ( $3 \mathrm{~min} / 20 \mathrm{~s}$ ) sample. It is readily seen that the initial bacterial inactivation becomes slower as the numbers of recycling increases. Fig. 7 shows that a decrease of $7 \log _{10}$ in the bacterial concentration within $30 \mathrm{~min}$ takes place upon recycling of the photocatalyst
Table 3

Surface atomic concentrations of elements during $E$. coli inactivation on $\mathrm{TiN}-\mathrm{Ag}$ polyester ( $3 \mathrm{~min}-20 \mathrm{~s}$ ) sputtered sample under Osram light ( $400-700 \mathrm{~nm}$ ) 18W/827 lamp.

\begin{tabular}{llllrl}
\hline TiN-Ag & O 1s & Ti 2p & N 1s & Ag 3d & C 1s \\
\hline$t=0$ min & 23.82 & 3.91 & 5.52 & 5.63 & 52.28 \\
$t=0$ min (contacted 3 s with bacteria) & 27.30 & 1.12 & 4.95 & 17.50 & 62.64 \\
$t=30$ min (contacted with bacteria) & 26.87 & 0.31 & 5.42 & 14.31 & 49.62 \\
$t=60$ min (contacted with bacteria) & 27.69 & 1.56 & 2.28 & 38.07 & 41.49 \\
$t=120$ min (contacted with bacteria) & 28.80 & 1.39 & 2.35 & 25.97 & 34.22 \\
\hline
\end{tabular}

sample up to the 8 th cycle. This is a reduction of 7 orders of magnitude in the initial bacterial concentration within $30 \mathrm{~min}$.

The time of inactivation as a function of the initial $E$. coli concentration was explored for concentrations of $10^{8}, 10^{7}$ and $10^{6} \mathrm{CFU} / \mathrm{mL}$. The time of inactivation was observed to decrease about $50 \%$ when the initial concentration of bacteria was reduced stepwise by one order of magnitude. This experiment was carried out to ensure that our catalyst follows normal inactivation behavior when interacting with E. coli, taken longer times to inactivate a higher initial CFU charge.

3.4. Ion-concentration release during E. coli inactivation determined by ICPS

Fig. 8 presents the release of ions from polyester samples sputtered with Ag, TiN-Ag and TiN. For Ag-sputtered samples up to the 

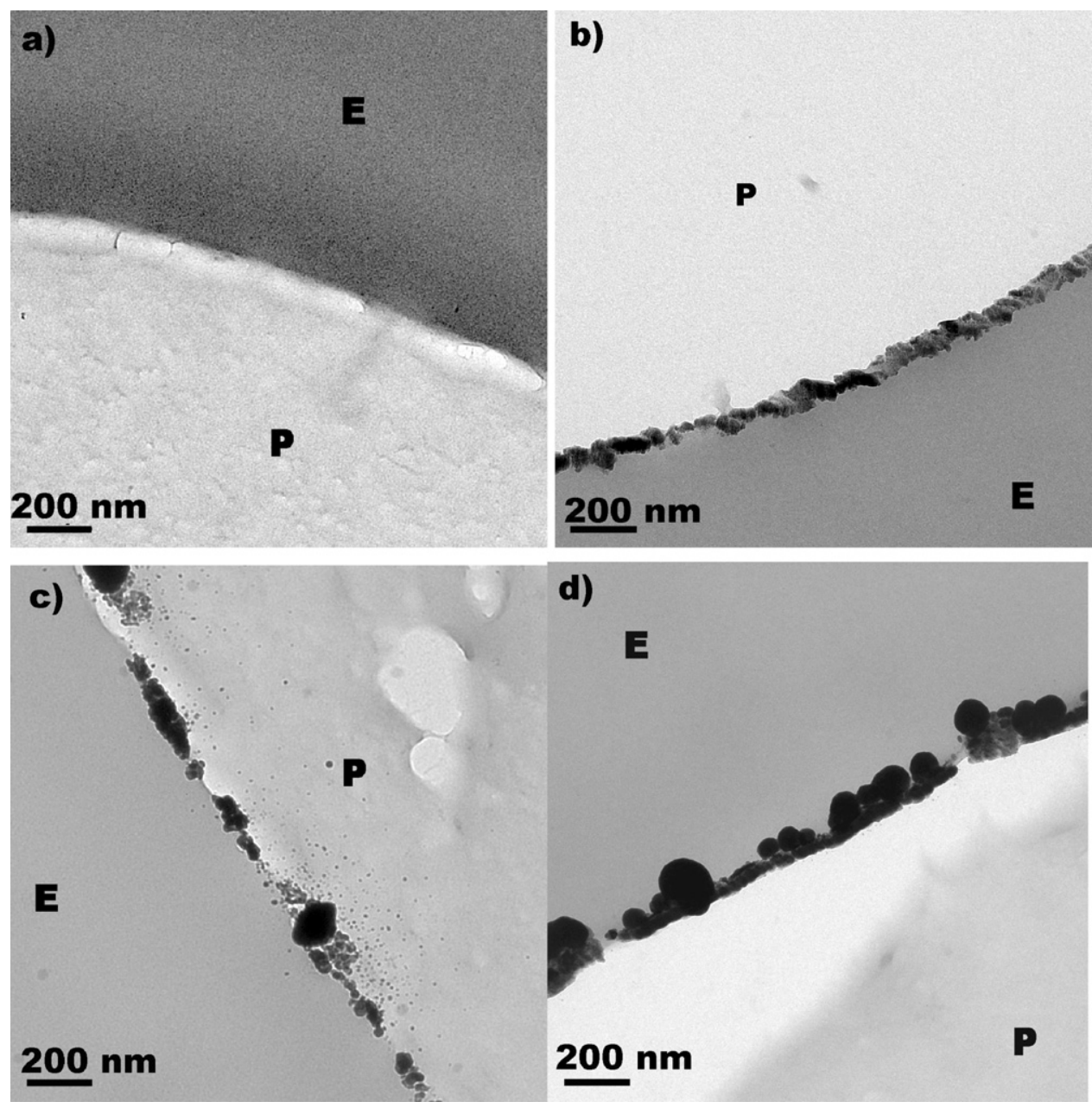

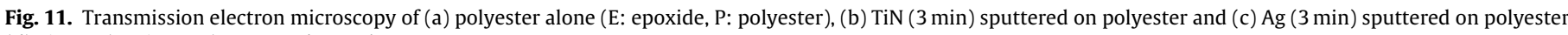
(d) TiN-Ag ( 3 min-20 s) sputtered on polyester.

8th cycle the level of Ag-release is seen to be 6 and $8 \mathrm{ppb} / \mathrm{cm}^{2}$. In the case of TiN-Ag samples the Ag-release was observed to decrease with the number of cycling's down to $5 \mathrm{ppb} / \mathrm{cm}^{2}$. Ag-ions were formed by oxidation of the Ag-loaded polyester surface in contact with reaction media. The release of Ag-ions $>0.1 \mathrm{ppb}$ has shown significant antimicrobial effect and higher Ag-ions $>35 \mathrm{ppb}$ can be toxic to human cells $[9,16]$. The antimicrobial performance of $\mathrm{Ag}$ is dependent on the Ag-ion release and these Ag-ions will be identified below in the section related to XPS.

The TiN polyester samples maintained about $14 \mathrm{ppb} / \mathrm{cm}^{2}$ releases of Ti-ions. The excellent intrinsic biocompatibility of TiN has been well documented in biomedical applications $[16,19,33]$. Bactericidal kinetics and a low cytotoxicity are the two essential requirements for bactericide surfaces and long-term tests using the catalyst presented in this study are under way in our laboratory.

\subsection{Diffuse reflectance spectroscopy and visual perception of polyester coated samples}

The rough UV-vis reflectance data cannot be used directly to assess the absorption coefficient of the loaded polyester because of the large scattering contribution to the reflectance spectra. Normally a weak dependence is assumed for the scattering coefficient $S$ on the wavelength. The values of KM/S for each sample in Fig. 9a are proportional to the absorption coefficient and parallel the bacterial inactivation kinetics for each sample shown previously in Fig. 3.
In Fig. 9a, the increase in Ag-sputtering time when going from $10 \mathrm{~s}$ to $20 \mathrm{~s}$ leads to an increase in the absorption peak around $400 \mathrm{~nm}$. This is due to localized surface plasmon resonance [34-36]. Fig. 9a; trace 1 show that plasmons on the silver surface for the TiN-Ag (3 min-20 s) enhance the bacterial inactivation kinetics on TiN-layers under light. Fig. 9a suggests a TiN electron transfer to the Ag-plasmons leading in a second stage to a faster inactivation of the bacteria adsorbed on the TiN-Ag-surface. A further increase in Ag sputtering time to $30 \mathrm{~s}$ (Fig. 9a, trace 4) decreased the absorption peak at $310 \mathrm{~nm}$ and did not shorten the bacterial inactivation in Fig. 3. At a higher Ag-concentration $>20 \mathrm{~s}$ sputtering time (see Table 1 ), the $\mathrm{Ag}$ acts as a carrier recombination center. A Schottky barrier builds up at the $\mathrm{TiO}_{2} / \mathrm{Ag}$ interface promoting charge separation [35-37]. The TiN low absorption in Fig. 9a, trace 1 is also consistent with the longer bacterial kinetics due to TiN (Fig. 2) compared to TiN-Ag.

Sputtering for $20 \mathrm{~s}$ introduces the most suitable Ag-level of $0.023 \mathrm{wt} \% / \mathrm{wt}$ polyester. Sputtering for $30 \mathrm{~s}$ loads the polyester with $0.050 \mathrm{wt} \% / \mathrm{Ag} /$ wt polyester. By XRD no metallic Ag was found on polyester by due to the low amount of Ag-deposited on the polyester.

Fig. 9b shows the values of KM/S for Ag-sputtered polyester samples. Since the Ag-absorption is similar in Fig. 9a and b, it is not the light absorption by Ag the determinant parameter for the bacterial inactivation kinetics but the different interfacial microstructure of $\mathrm{Ag}$ on polyester when $\mathrm{TiN}$ is present that determines the kinetics of bacterial inactivation. The charge transfer in the TiN-Ag 

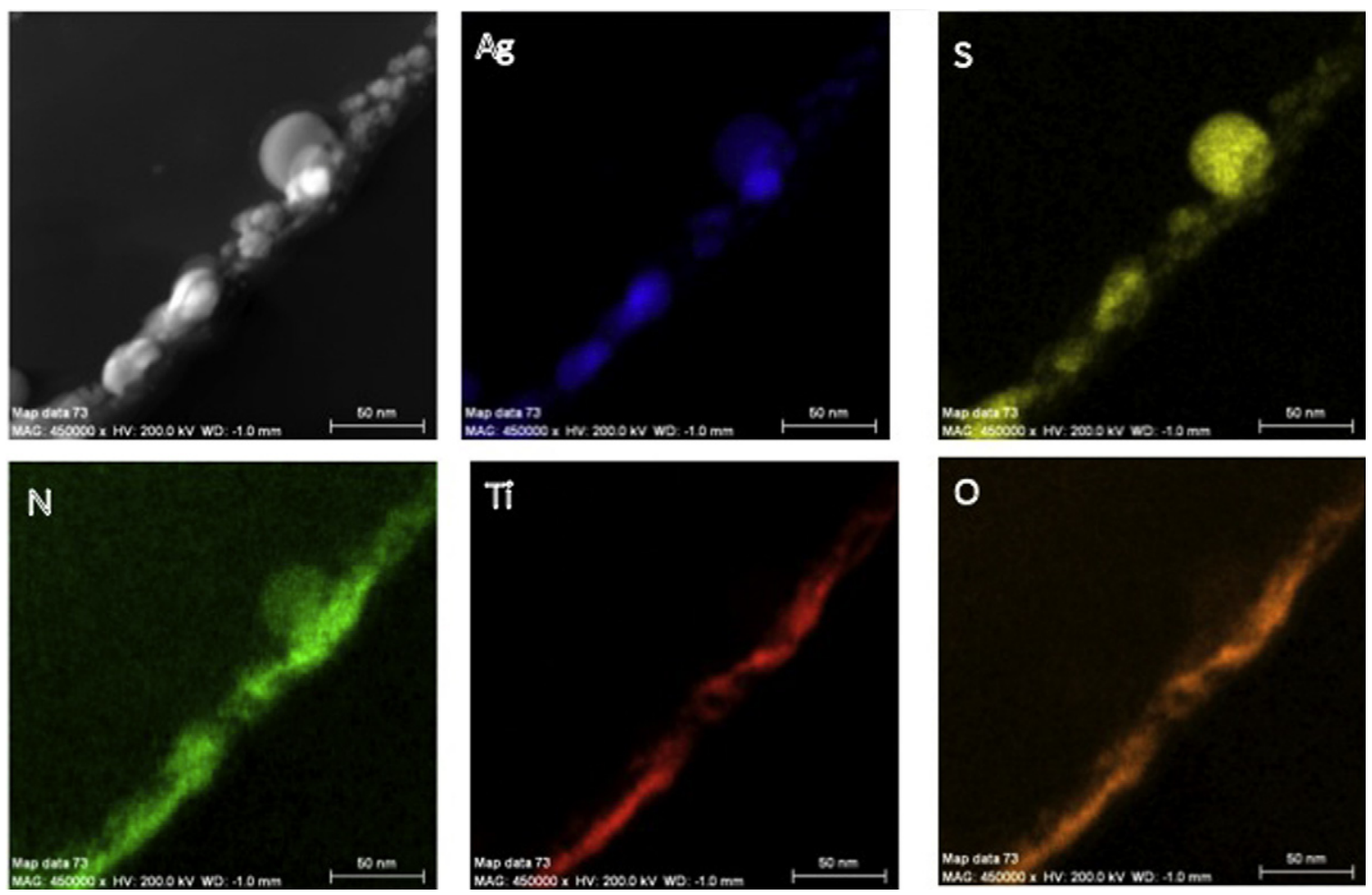

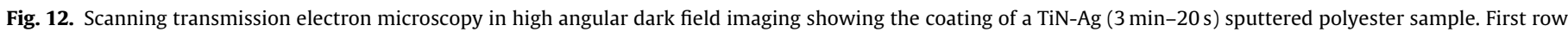
left image of the layer with all the components and the following five images refer to $\mathrm{Ag}, \mathrm{S}, \mathrm{N}, \mathrm{Ti}$ and $\mathrm{O}$.

samples under light occurs more effectively than in the case of Agsamples. This is in consistent with the bacterial inactivation kinetics reported in Fig. 3 compared to Fig. 4. The difference in the interface microstructure for $\mathrm{Ag}$ and $\mathrm{TiN}-\mathrm{Ag}$ layers will be reported by TEM in Section 3.6.

The visual perception of sputtered samples is shown in Fig. 10. The polyester alone is white but when sputtered with TiN for $3 \mathrm{~min}$ it becomes brown. Sputtering Ag for $20 \mathrm{~s}$ led to a dark gray color polyester that became close to black when the Ag was sputtered on TiN for $20 \mathrm{~s}$. The dark gray color corresponds to the $\mathrm{Ag}_{2} \mathrm{O} / \mathrm{Ag}^{0}$ with a band-gap of $0.7-1.0 \mathrm{eV}$ and an absorption edge of $\sim 1000 \mathrm{~nm}$ as mentioned previously in Section 3.1.

\subsection{Electron microscopy of polyester modified samples (TEM) and energy dispersive spectroscopy of the TiN-Ag polyester surface (EDS)}

Fig. 11 presents the TEM of: (a) the polyester surface sample, (b) the TiN layer sputtered on polyester for 3 min presenting a width of $30-50 \mathrm{~nm}$ equivalent to $150-250 \mathrm{TiN}$ layers, (c) polyester-Ag sputtered for 3 min showing dense Ag-cluster between 30 and $80 \mathrm{~nm}$, (d) TiN-Ag sputtered on polyester for $3 \mathrm{~min}$ and $20 \mathrm{~s}$ respectively. The uniformity of the Ag-clusters on the TiN film was observed to be much higher than the Ag-sputtered on the polyester alone (data not shown). This may explain the faster inactivation kinetics reported in Fig. 3 compared to Fig. 4.

Based on the size of the Ag-clusters found in Fig. 11c and d it is possible to see that the $\mathrm{Ag}$ clusters on the polyester surface will not enter through the porins of the E. coli of 1.0-1.1 nm. But these pore let pass the Ag-ions formed when the Ag-oxidizes while interacting with the bacterial cell $[9,38-40]$.

As a result of the interaction between the high-energy electrons Fig. 12 shows the scanning transmission electron microscopy in high angular dark field imaging for TiN-Ag (3 min-20 s) sputtered polyester sample. First row left image of the layer with all the components. Since each atom in the EDS microscopy emits their specific X-rays the continuous layers of $\mathrm{Ag}, \mathrm{S}, \mathrm{N}, \mathrm{Ti}$ and $\mathrm{O}$ are shown separately in Fig. 12.

\subsection{Photoelectron spectroscopy (XPS) of the Ag and Ti-species on the modified polyester}

Table 2 shows the surface atomic composition percentage for the main elements of TiN polyester as a function of the bacterial inactivation time. The $C$ at time zero increases upon $3 \mathrm{~s}$ contact with bacteria as expected and concomitantly the Ti2p and $\mathrm{N}$ peaks decreases due to the bacteria coverage. After $180 \mathrm{~min}$ the $\mathrm{C}$ is seen to further decrease due to bacterial inactivation. Table 3 for the TiN-Ag polyester shows a different evolution for the atomic surface concentration with respect to the values reported in Table 3. The C-concentration decreases as expected up to $120 \mathrm{~min}$ due to the bacterial inactivation within this period but the Ag concentration is seen to increase after $3 \mathrm{~s}$. The antimicrobial activity of $\mathrm{Ag}$ is dependent on the $\mathrm{Ag}^{+}$-cation strongly binding to the electron donor groups $\mathrm{S}, \mathrm{O}$ and $\mathrm{N}$ of the bacterial cell wall. Only a trend can be reported for the values of $C$ and $A g$ reported in Tables 2 and 3 by XPS for the surface concentrations of these 2 elements.

Fig. 13 presents the Ti $2 \mathrm{p}_{3 / 2}$ doublet found for samples of TiN-Ag (3 min-20s) contacted $3 \mathrm{~s}$ with bacteria. The deconvolution of the XPS-signal has been carried out by means of the Casa-XPS program (see Section 2.8). The TiN species shows a peak at $455.22 \mathrm{eV}$, the $\mathrm{Ti}^{3+}$ doublet is seen at $456.22 \mathrm{eV}$ and the $\mathrm{Ti}^{4+}$ doublet at $258.43 \mathrm{eV}$ [26]. Fig. 13 presents the evidence for $\mathrm{TiO}_{2}$ formation on the polyester when sputtering TiN under the experimental conditions described above in Section 2.1 and discussed in Section 3.1.

Fig. 13 presents in the middle left inset the shift of the Ti2 $\mathrm{p}_{2 / 3}$ peak during $E$. coli inactivation of the TiN-Ag ( 3 min-20 s) sample within $180 \mathrm{~min}$ from $459.2 \mathrm{eV}$ to $458.7 \mathrm{eV}$. This shift is further evidence for redox processes taking place on the polyester surface involving $\mathrm{Ti}^{4+} / \mathrm{Ti}^{3+}$ during bacterial inactivation. Shifts in the peaks 


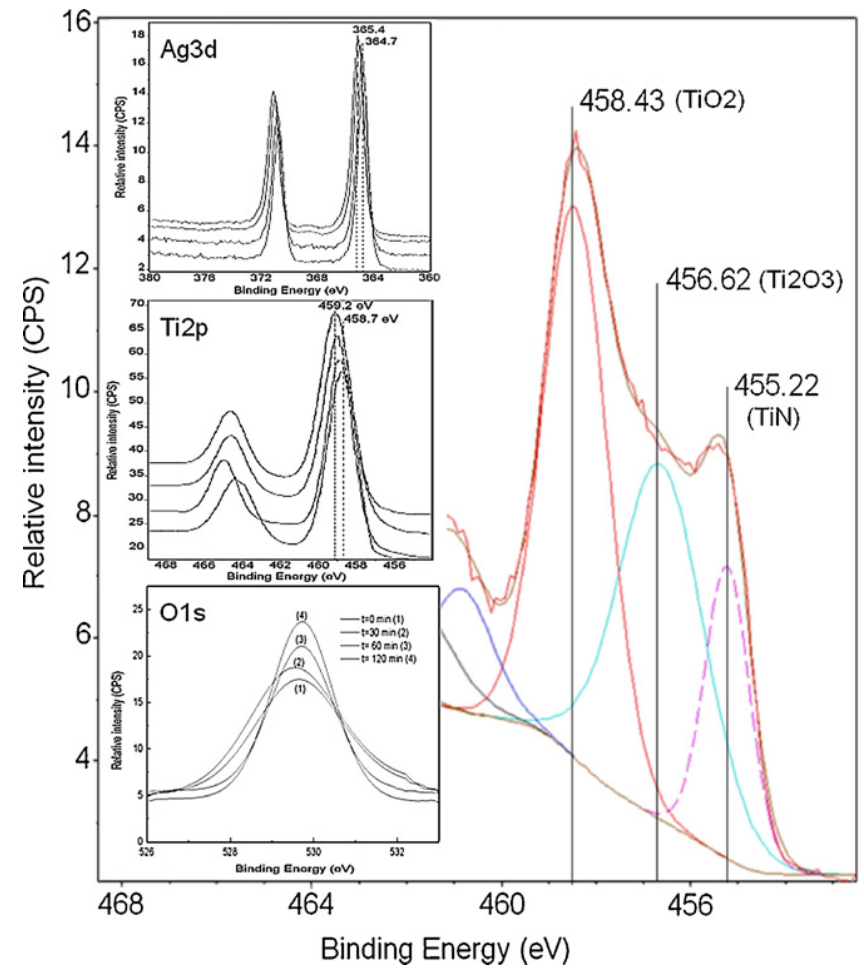

Fig. 13. Right hand side: XPS of the Ti $2 \mathrm{p}_{3 / 2}$ doublet from the TiN-Ag ( 3 min-20s) sample contacted with bacteria for $3 \mathrm{~s}$. (a) Upper inset: $\mathrm{Ag} 3 \mathrm{~d}_{5 / 2}$ shift between times zero and 180 min during E. coli inactivation on TiN-Ag ( 3 min-20 s). (b) Middle inset: Ti $2 \mathrm{p}_{3 / 2}$ shift during E. coli inactivation on TiN-Ag ( 3 min-20 s) between zero and $120 \mathrm{~min}$. (c) Lower inset: The $\mathrm{O} 1 \mathrm{~s}$ during E. coli inactivation on TiN-Ag (3 min-20 s) between zero and 120 min.g.

$\geq 0.2 \mathrm{eV}$ reflect valid changes in the oxidation states of the elements [25,27].

Fig. 13 presents in the upper inset the $A g 3 d_{5 / 2}$ peak stepwise shift from $364.7 \mathrm{eV}$ to $365.4 \mathrm{eV}$ assigned to the shift from $\mathrm{Ag}^{0}$ to $\mathrm{Ag}^{1+/ 2+}$ ionic species within 180 min during $E$. coli inactivation on a TiN-Ag (3 min-20 s) polyester sample [9,27]. The XPS shift lies in the region related to the oxidation states between $\mathrm{Ag}^{0}$ and $\mathrm{Ag}^{2+}$. Since these shifts were observed by XPS on the upper polyester modified layers this is indicative for the presence of Ag ions layers located mainly at the Ag-interface.

Fig. 13 presents in the lower inset the $01 \mathrm{~s}$ increase between time zero and 120 min during $E$. coli inactivation. It is readily seen that the XPS-signal increases due to $\mathrm{O}$-rich functionalities produced during the inactivation/oxidation of the bacterial organic moiety. This last observation will be described in more detail below in the section related to Fig. 14.

Fig. 14 shows the ratio found for the XPS signals for the oxidative species $(\mathrm{C}-\mathrm{O})$ and the reduced initial polyester groups $(\mathrm{C}=\mathrm{C})$ during the bacterial inactivation/oxidation on a TiN-Ag ( 3 min-20s) and a TiN sputtered sample. The increase of the surface $O$ is due to the appearance $\mathrm{C}-\mathrm{OH}, \mathrm{C}-\mathrm{O}-\mathrm{C}$ and carboxyl species as the $E$. coli inactivation time progresses [41]. At the same time, the total C-content decreases with reaction time due to the bacterial inactivation on the modified polyester surfaces and is monitored by the progressive decrease of the $\mathrm{C}-\mathrm{C}$ signals as a function of time (Tables 2 and 3 ). The ratio of the peaks area of the $\mathrm{C}-\mathrm{C}$ species (including the reduced $\mathrm{C}$-forms $\mathrm{C}=\mathrm{C}, \mathrm{C}-\mathrm{H}$ ) with (BE) of $285 \mathrm{eV}$ and the deconvoluted oxidized $\mathrm{C}$-forms of: $\mathrm{C}-\mathrm{OH}, \mathrm{C}-\mathrm{O}-\mathrm{C}$ and carboxyl functionalities with $\mathrm{BE}$ at $286.1 \mathrm{eV}, 287.0 \mathrm{eV}$ and $289.1 \mathrm{eV}$ respectively [42]. The increase in the ratio $\mathrm{C}-\mathrm{O} / \mathrm{C}=\mathrm{C}$ is shown in Fig. 14 up to $180 \mathrm{~nm}$.

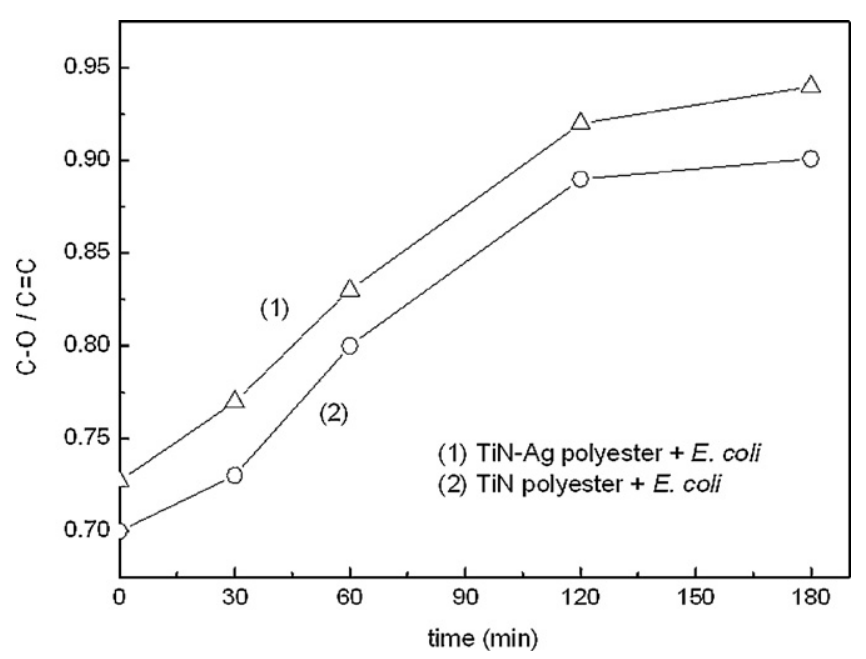

Fig. 14. Ratio of oxidized carbon and reduced carbon $(\mathrm{C}-\mathrm{O} / \mathrm{C}=\mathrm{C})$ on $\mathrm{TiN}-\mathrm{Ag}$ ( $3 \mathrm{~min}-20 \mathrm{~s})$ and TiN (3 min) samples in presence of $E$. coli under light Osram (400-700 nm) $4 \mathrm{~mW} / \mathrm{cm}^{2}$.

\section{Conclusions}

Evidence is presented for TiN and TiN-Ag films as bactericide films when exposed to low intensity visible/actinic light. The sputtering of TiN under layers on the rough polyester surface lead to a more uniform deposition of Ag-nanoparticles compared to the sputtering Ag directly on the polyester. Excitation of the surface plasmons led to the photo-enhancement of the rate of charge transfer from TiN-Ag to the adsorbed bacteria on the catalyst surface. The magnitude of the optical absorption for the TiN samples runs parallel to the kinetics observed for $E$. coli inactivation. This study present evidence for TiN and TiN-Ag thin films as promising bactericide films useful in hospital environments when exposed to low intensity visible/actinic light. Evidence is presented by XPS for $\mathrm{Ti}^{4+} / \mathrm{Ti}^{3+}$ redox processes during bacterial inactivation. The $\mathrm{Ag}$ on the TiN presented fairly stable plasmonic activity up to eight recycling.

\section{Acknowledgments}

We wish to thank the COST Action MP0804 Highly Ionized Impulse Plasma Processes (HIPIMS) and the EPFL for support of this work.

\section{References}

[1] F. Magnus, O.B. Sveinsson, S. Olafson, J.T. Gudmundsson, Journal of Applied Physics 110 (2011) 083306.

[2] P.J. Matsuo, T.E.F. Standaert, S.D. Allen, G.S. Oehrlein, Journal of Vacuum Science and Technology B 17 (4) (1999) 1435-1439.

[3] F. Magnus, A.S. Ingason, O.B. Sveinsoon, S. Olafsson, T.J. Gudmundsson, Thin Solid Films 520 (2011) 1621-1624.

[4] P.J. Kelly, H. Li, P.S. Benson, K.A. Whitehead, J. Verran, R.D. Arnell, I. Iordanova, Surface and Coatings Technology 205 (2010) 1606-1610.

[5] P.J. Kelly, H. Li, K.A. Whitehead, J. Verran, R.D. Arnell, I. Iordanova, Surface and Coatings Technology 204 (2009) 1137-1141.

[6] O. Baghriche, J. Kiwi, C. Pulgarin, R. Sanjinés, Journal of Photochemistry and Photobiology A 229 (2012) 39-45.

[7] T. Yuranova, G. Rincon, A. Bozzi, S. Parra, C. Pulgarin, P. Albers, J. Kiwi, Journal of Photochemistry and Photobiology A: Chemistry 161 (2003) 27-34.

[8] T. Yuranova, A.G. Rincon, C. Pulgarin, D. Laub, N. Xantopoulos, H.-J. Mathieu, J. Kiwi, Journal of Photochemistry and Photobiology A 181 (2006) 363-369.

[9] M.I. Mejía, G. Restrepo, J.M. Marín, R. Sanjines, C. Pulgarín, E. Mielczarski, J. Mielczarski, J. Kiwi, ACS Applied Materials \& Interfaces 2 (2010) 230-235.

[10] O. Baghriche, A.P. Ehiasarian, E. Kusiak-Nejman, A.W. Morawski, C. Pulgarin, R. Sanjines, J. Kiwi, Journal of Photochemistry and Photobiology A 227 (2011) 11-17. 
[11] O. Baghriche, A.P. Ehiasarian, E. Kusiak-Nejman, A.W. Morawski, C. Pulgarin, R. Sanjines, J. Kiwi, Thin Solid Films 520 (2012) 3567-3573.

[12] L. Geranio, M. Heuberger, E. Nowack, Environmental Science and Technology 43 (2009) 8113-8118.

[13] D. Hegemann, M. Amberg, A. Ritter, M. Heugeberg, Materials Technology 24 (2009) 41-45.

[14] D. Hegemannn, M. Hossain, M. Balazs, Progress in Organic Coatings 58 (2008) 237-240.

[15] D. Mihailović, Z. Saponjić, V. Vodnik, B. Potkonjak, P. Jovančić, J.M. Nedeljković, M. Radetić, Polymers for Advanced Technologies 22 (2011) 2244-2249.

[16] Thüringer Surface and Biomaterial Kolloquium, 13/15 September Zeulenroda,Germany.

[17] J. Liao, M. Anchun, Z. Zhu, Y. Quan, International Journal of Nanomedicine 13 (2010) 337-342.

[18] J. Thiel, L. Pakstis, S. Buzby, M. Raffi, C. Ni, D.-J. Pochan, S.I. Shah, Small 3 (5) (2007) 799-803.

[19] K. Page, M. Wilson, I.P. Parkin, Journal of Materials Chemistry 19 (2009) 3819-3831.

[20] S. Noimark, Ch. Dunnill, M. Wilson, I.P. Parkin, Chemical Society Reviews 38 (2009) 3435-3448.

[21] A.H. Foster, D.W. Sheel, P. Sheel, P. Evans, S. Varghese, N. Rutschke, H.M. Yates, Journal of Photochemistry and Photobiology A 216 (2010) 283-289.

[22] P.S.M. Dunlop, C.P. Sheeran, J.A. Byrne, M.A.S. McMahon, M.A. Boyle, K.G. McGuigan, Journal of Photochemistry and Photobiology A 216 (2010) 303-3010.

[23] C. Castro, R. Sanjines, C. Pulgarin, P. Osorio, S.A. Giraldo, J. Kiwi, Journal of Photochemistry and Photobiology A 216 (2010) 295-302.
[24] P. Osorio, R. Ruales, C. Castro, C. Pulgarin, R. Sanjines, A.-J. Rengifo, J.-C. Lavanchy, J. Kiwi, Journal of Photochemistry and Photobiology A 220 (2011) 70-76.

[25] J.B. Mathews, Epitaxial Growth Part B, IBM Thomas Watson Research Center, Academic Press, New York, 1975, pp. 382-436.

[26] C.D. Wagner, M.W. Riggs, E.L. Davis, G.E. Müllenberg (Eds.), Handbook of X-Ray Photoelectron Spectroscopy, Perkin-Elmer Corporation Physical Electronics Division, Minnesota, 1979.

[27] D.A. Shirley, Physical Review B 5 (1972) 4709-4714.

[28] A. Fujishima, T. Tao, D. Tryk, Journal of Photochemistry and Photobiology C 1 (2000) 1-21.

[29] A. Mills, Journal of Photochemistry and Photobiology A 108 (1997) 108.

[30] J.P. Kelly, R.D. Arnell, Vacuum 56 (2000) 159-172, and references therein.

[31] R. Houk, B. Jacobs, F. Gabay, N. Chang, D. Graham, S. House, I. Robertson, M. Allendorf, Nano Letters 9 (2009) 3413-3418.

[32] A.P. Ehiasarian, Pure and Applied Chemistry 82 (2010) 1247-1258.

[33] A. Wisbey, P.J. Gregson, M. Tuke, Biomaterials 8 (1987) 9477-9480.

[34] L. Gang, B.G. Anderson, J. Grondelle, R.A. van Santen, Applied Catalysis B 40 (2002) 101-107, and references therein.

[35] H. Tada, K. Teranishi, Y. Inubushi, S. Ito, Langmuir 16 (2000) 3304-3309.

[36] D.P. Dowling, A.J. Betts, C. Pope, M.L. McConnell, R. Eloy, M.N. Arnaud, Surface and Coatings Technology 163-164 (2003) 637-640.

[37] D. Griffiths, Introduction to Quantum Mechanics, 2nd ed., Prentice Hall, 2004.

[38] H. Nikaido, Journal of Biological Chemistry 269 (1994) 3905-3908.

[39] A.P. Pugsley, C.A. Schnaitman, Journal of Bacteriology 133 (1978) 1181-1189.

[40] X.Z. Li, H. Nikaido, K.E. Williamns, Journal of Bacteriology 179 (1997) 6127-6132.

[41] F. Mazille, T. Schoettl, C. Pulgarin, Applied Catalysis B 89 (2009) 635-644.

[42] S. Yumitori, Journal of Materials Science 35 (2000) 139-146. 